\title{
Sub-Saharan Countries in the Age of Informational Globalization: On Preservation of Cultural Identity
}

\author{
Konstantin A. Pantserev \\ St. Petersburg State University, St. Petersburg, Russia
}

\begin{abstract}
The paper is devoted to the problem of the development of information technologies in Sub-Saharan countries. The author comes to a conclusion that the up-to-date level of the development of information technologies in Sub-Saharan countries doesn't give us an opportunity to estimate the close equal integration of the region into the global information and communication space. African countries don't have appropriate financial and technological resources which seem to be necessary when creating the well-developed information and telecommunication infrastructure on their territory. The author argues that in order to reach the level of the development of well-developed nations African states are forced to seek the aid of Western countries which use the technological and financial dependence of their African partners as the strong instrument of preservation of their influence in the region. In current circumstances it would be very difficult for African countries to create a self-reliant information society and to preserve their cultural identity in the upcoming information age.
\end{abstract}

Keywords: Sub-Saharan countries, information society, information technologies, information space, Africa

\section{Introduction}

Nowadays when knowledge, information and information technologies become an integral component of the humans life, articles of trade and important strategic resources the development of national information infrastructure is recognized by the international community as the most important strategic task of the State.

Today we can observe the situation when the transformation into a knowledge-based economy becomes one of the most important strategic priorities of the policy of almost every nation both well-developed and developing ones. So do the States of Sub-Saharan Africa as well.

In Kenya, for example, there is a special document entitled Kenya Vision 2030 which has been adopted in 2008. This document represents a general programme of the national development by the year 2030. The main goal is to "create a globally competitive and prosperous nation with the high quality of life by 2030" (Kenya Vision 2030, n.d.)

According to the programme they underline three pillars in the development of the country: an economic one, a social one and a political one. And information technologies form the backbone of every pillar. Thus one should concern the development of the Information and communications technology (ICT) sector as the key factor in the achievement of the sustainable social and economic growth of the country.

In the "Vision" they underline the necessity of elaboration and implementation of special training courses

Konstantin A. Pantserev, Associate Professor, Department of Theory and History of International Relations, St. Petersburg State University. 
aimed on the increase of computer literacy of Kenyans. The programme also pays great attention to the problem of the computerization of Kenyan schools in order to grow up a new generation of Kenyans who are ready to live and to work in the information age. Besides, the "Kenya Vision 2030" suppose the elaboration of complex of measures aimed on the stimulation of the usage of information technologies in research centers, universities and commercial organizations.

But it is evident that this document provides only the general vision of the development of the country and all tasks mentioned in the "Vision" should be reflected in the short-term and medium-term national programmes of the development.

There is a similar document in Nigeria where it is entitled the "Vision 2020". It represents also the general concept of the social and economic development of the country which has been adopted by the Nigerian government in 2007. According to the "Vision" by the year 2020 the economy of Nigeria must enter the top-20 and Nigeria would be able to play the key role in the social and economic development of the entire continent and also would become a pronounced actor in the global economic and political arena (Nigeria Vision 2020, n.d.).

Information and telecommunication technologies should become an effective instrument which would help Nigeria to achieve the goal mentioned in the "Vision" and to ensure the sustainable social and economic growth of the country.

The government of Ghana also pays more and more attention to the development of the ICT sector. In the year 2003 they have adopted a special policy statement for the realization of the general vision in order to transform Ghana into an information-rich and knowledge-based society. The document was named "The Ghana ICT for accelerated development policy" (The Ghana ICT for accelerated development policy, n.d.).

In this document there have been underlined 10 key drivers of the policy:

(1) ICTs as a Social-Enabler (Education, Health, Poverty-Reduction, Income-Distribution);

(2) ICTs as an Enabler of rapid Socio-Economic development;

(3) ICTs as an Enabler of Government Administration and Service Delivery;

(4) ICTs as a Facilitator of Electronic Government and Electronic Commerce Initiatives;

(5) ICTs as an Engine of the Service Sector;

(6) ICTs as an Enabler of Knowledge-driven Industrial development;

(7) ICTs as an Enabler of the Agriculture Sector;

(8) ICTs as a Driver of Private Sector Development;

(9) ICTs as an Agent for Wealth Creation;

(10) ICTs as a Tool for Bridging the Gender inequality Gap in Social, Economic and Political development.

So we can conclude that the ICT forms the backbone of national development of every country in modern world. And the policy poses a number of principal questions (The Ghana ICT for accelerated development policy, n.d.):

(1) Where we are as a nation?

(2) Where do we want to get to as a nation?

(3) When do we want to get there?

(4) What do we need to do in order to get there?

And there is the only answer-through the development of the ICT-sector. In order to achieve such goal 
authors of the Program underline 14 key priorities, 14 pillars (The Ghana ICT for accelerated development policy, n.d.).

(1) Accelerated Human Resource Development;

(2) Promoting ICTs in Education-The Deployment and Exploitation of ICTs in Education;

(3) Facilitating Government Administration and Service Delivery: Promoting Electronic Government and Governance;

(4) Facilitating the Development of the Private Sector;

(5) Developing an Export-Oriented ICT Products and Services Industry;

(6) Modernization of Agriculture and the Development of an Agro-Business Industry;

(7) Developing a Globally Competitive Value-Added Services Sector-A Regional Business Service and ICT Hub;

(8) Deployment and Spread of ICTs in the Community;

(9) Promotion of National Health;

(10) Rapid ICT and Enabling Physical Infrastructure Development;

(11) Legal, Regulatory, and Institutional Framework Provisions;

(12) Research and development, Scientific and Industrial Research Capacity Development;

(13) Promoting Foreign and Local Direct Investment Drive in ICTs;

(14) Facilitating National Security, Law and Order.

It is completely impossible to have a definite attitude to all those programmes elaborated by African countries. From the first side one can mark that African countries define very ambitious and almost unreachable tasks.

There are great obstacles on the way of the comprehensive achievement of all these goals. As it is well-known the smooth transformation into an information society is possible only incase if the society has successfully passed two stages of the development - an agrarian and an industrial one. But the problem is that African countries are still in the agrarian stage of the development. And when creating an information society in the region they try to jump over highly developed postindustrial stage of the development by skipping an industrial one.

It is evident that the up-to-date level of the development of Sub-Saharan countries doesn't give them an opportunity to estimate close equal integration into the global information and communication space. The vast majority of African countries don't have enough financial and technological resources in order to create a well-developed information and telecommunication infrastructure on their territory.

That's why when creating African information and communication space in order to reach the level of the development of Western countries Sub-Saharan countries are forced to seek the aid from their more developed Western partners which make them start economic and political transformations exclusively aimed on the creation of favorable conditions for foreign investments. This process which was named the "structural reconstruction" of economies of African countries initially has been controlled by the State but very soon it has transformed into the uncontrolled process with the only value and slogan: "full liberalization". As a result of such policy, almost the whole information and communication industry of the continent will be privatized by foreign investors very soon, but not African.

Thus mostly under the pressure of world financial institutions such as the International Monetary Fund and the World Bank Kenyan government was forced to start the process of economic transformations of national 
ICT sector of the country in the year 1998. As a result of such transformations National Post and Telecommunication Corporation has been liquidated and they started the policy of full liberalization and privatization of the sector. Nowadays French telecommunication corporation France Telecom is majority shareholder of former national Kenyan telecommunication company Telcom Kenya.

The privatization of the Senegalese telecommunication company Sonatel in 1997 was also a forced measure due to the necessity of the complete modernization of facilities of the company. A French corporation France Cables Radio which was a branch of France Telecom has become a majority shareholder of the company.

Due to the financial and technological dependence of African countries from the well-developed nations the vast majority of national programs of the development of African countries are aimed mostly on the creation of favorable conditions for the attraction of foreign (non-African) investors into the ICT sector of the region. Besides, all those national programs of the development represent a simple retranslation of recommendations coming from global forums such as "G8" summits and World Summit of Information Society where Western countries seem to be the only decision makers.

\section{Sub-Saharan Countries in the Age of Information Globalization: Prospects of Independent Development}

After more than 10 years of sustainable growth of ICT sector in Africa, we can ascertain the comparative level of the development of African ICT industry. The monitoring of the most significant initiatives in the ICT-sector undertaken by a number of African countries, shoes attempts to build the Pan-African information and communication space and to provide the universal access to technologies.

The Program of the development of optic-fiber communications in Africa has been signed in 2003. They were going to build more than 25,000 miles of optic-fiber lines all-over the continent (NEPAD E-Africa Commission, 2014).

Nowadays one can ascertain that the greatest part of this huge and very important work has been done. The backbone of African informational and communication infrastructure has been constructed and it caused the significant reduction of prices of the Internet-connection in the vast majority of African countries.

From one hand, we can see the very impressive geography of Pan African optic-fiber cable system that starts in Portugal and goes alongside the West African shore via Cape Town, then in Johannesburg they start the East African submarine cable system that goes alongside the East African shore through Mombasa (Kenya) via the Emirates (Chasia, 2005, p. 15; International Telecommunication Union, 2007). But from the other hand one can mark that the vast majority of optic-fiber lines is concentrated alongside an ocean shore of African countries with very week penetration deep into the continent. For example in Kenya all optic-fiber lines are concentrated alongside the line Mombasa-Nairobi-Kisumu.

But the main point is that African states don't dispose enough financial base to construct the informational and communication backbone of the continent without aid of international financial organizations, such as International Monetary Fund, World Bank and French Agency of the Development. For example, French Agency of the Development has invested $850 \mathrm{mlns}$ of euros to the realization of this project, and the World Bank has invested 165 mlns of dollars (NEPAD E-Africa Commission, 2014). These facts give us an opportunity to conclude that Western countries still go on with participation in the realization of the most significant infrastructural projects for the continent in order to preserve their influence on the management of 
the Pan African informational and communicational infrastructure which is under construction.

The importance of the realization of such infrastructural project even with the aid of Western partners is evident. It causes significant reduction of prices of Internet-connections for African countries. And Western investors get a control of all these new optic-fiber lines which pass alongside the Continent.

But the construction of the modern information and telecommunication infrastructure in Africa is not the only task for African countries if they pretend to become an equal part of the global information and communication space. The second point is to create modern innovation centers in Africa in order to give African countries an opportunity to produce their own technologies which would be maximally adopted for the necessity of African citizenry.

Finally, such very ambitious projects have appeared—one in Kenya and the second in Ghana. On January 2013 the government of Kenya has declared the beginning of the construction of the "Silicon savanna"-Konza Techno City - a huge innovation complex not far from Nairobi (Konza Techno City, n.d.).

And on March 2013, the President of Ghana, Jon Mahama has declared the beginning of the construction the new innovation center which should be specialized in the sphere of telecommunications. They are going to finish this project which will cost about $\$ 10$ blns in three years. In Ghana they named this huge innovation center the "Hope City". It should be a six towers complex. The height of one tower should exceed 270 meters. So the new skyscraper will become the highest building in Africa (Kermeliotis, 2013).

But the question is that where the States of Sub-Saharan Africa could find enough money in order to finalize such very important projects not only for Kenya or Ghana but for the Continent as a whole. It is evident that the only way to realize these projects is to throw the attraction of private investments. But the State should coordinate this process. So it is important to establish an effective public-private partnership. And the State should preserve the regulation function in governance of these innovation complexes. Besides, it is also very important to attract not only foreign investments, but also local ones. Otherwise Western companies will get the global control over the whole ICT industry on the Continent. And it'll be completely impossible to overcome such dependence.

Finally, Konza Techno City and the Hope City should become technological hubs for the development of local digital content in Africa. Of course, for the beginning they can start to use Western technologies but later, step by step, it is necessary to begin to produce local computers and software which should be maximally adapted to the necessity of African citizenry. To our opinion, only in case of the realization of these two projects both in Kenya and Ghana, African countries can finally start to produce their own, African technologies and States of Sub-Saharan Africa would be able to become an equal part of the global information and communication space. But in case that functioning of those innovation complexes are based only on foreign investments and technologies, both Konza Techno City and Hope City would become the new and very effective instrument of preservation of Western influence in the region.

Unfortunately, nowadays in Africa there dominates the point of view that "We (Africans) need Europe to rescue from the poverty". Such statement we have heard from the president of Ghana John Mahama in his speech on the opening ceremony of the Global convention on African studies which was held in the University of Ghana in October 2013. And as soon as one can hear such statements from heads of African countries, it is completely impossible to estimate it as an independent development of states of the region. Taking to account African realities we'd like to state that there is the only thing which is worse than the presence of foreign investors - the lack of them. 
When Western countries helping the less developed African partners in the creation of African information and communication space, they follow their own strategic and economic interests and don't take the interests of African citizenry into account. The ICT sector of Sub-Saharan countries which is under construction is attached to the Western typological model and standards and leave out of account national interests and specifics of African countries. That's why nowadays when explaining the process of the modernization in Africa they very often use the word "westernization" ("westernization" is "modernization") (Adamu, 2007, p. 85).

It is evident that in current circumstances would be very difficult for Sub-Saharan countries to estimate equal integration into the global information and communication space and to preserve their cultural identity in the upcoming information age. As a result, Sub-Saharan countries will roll down onto the periphery of global information and communication processes despite of all efforts undertaken by African states in order to ensure the sustainable social and economic growth and reach the current level of the development of Western countries.

But to our opinion African countries can reduce the level of their financial and technological dependence from the West. The solution of this problems lies through the intensification of processes of Pan-African integration and creation of Pan-African information and communication space in construction of which the role of well-developed Western nations should be minimized.

But we don't believe that in nearest future there would be established the real, not only on the paper, unity of African States. There is a great number of political, cultural and ethnic conflicts in Africa which put serious obstacles on the way of Pan-African integration. But nevertheless we can observe several positive signs. For example the vast majority of African leaders finally succeeded in the elaboration of the common view of problems of the continent.

Almost all countries of the region are sure that it is necessary to pay increased attention to the development of their ICT industry. So the necessity of the creation of information and telecommunication infrastructure and the elaboration of the joint strategy of the development of the ICT sector could become the common idea which would consolidate the vast majority of African countries.

We'd like to remind that the idea of the achievement of the real unity of African states in order to solve the most significant problems of the continent and to ensure an independent development is not a new one. Initially it belongs to Kwame Nkrume, the first president of Ghana who dreamed about the unity of African countries. In a great number of his speeches he stated that "Africa must unit" (Nkrumah, 2007). But we can't say that up-to-date situation is completely different.

To our opinion, the Common Market for Eastern and Southern Africa (COMESA) nowadays is the only more or less effective regional alliance in Africa. But today they start to use the necessity of the development of the ICT sector as an instrument which could initiate the process of real Pan-African integration. In 2007, a special protocol concerning the future mutual cooperation in the sphere of ICT was signed in Kigali (Rwanda). Initially this protocol has been signed by Botswana, Democratic Republic of Congo, Lesotho, Madagascar, Malawi, Mauritius, Rwanda, South Africa, Tanzania, Uganda, Zambia and Zimbabwe.

We'd like to name the main purposes of the protocol (NEPAD E-Africa Commission, 2014).

(1) Ensure the development of optic-fiber cable system in Eastern and Southern parts of the Continent;

(2) Further the attraction of private investments to the development of information and communication infrastructure of the region;

(3) Promote the integration of national information networks of African countries which already exist into 
the single Pan-African one;

(4) Survey legal, political, bureaucratic obstacles on the way of creation of the Pan-African optic-fiber cable system and elaborate suggestions for African governments how to overcome them;

(5) Further the creation and usage of the well-developed information and communication infrastructure of the region in order to ensure the trans-border exchange of information;

(6) Ensure the creation of the information and telecommunication infrastructure which would be conducive to the strengthening of processes of economic, social and cultural integration of African countries;

(7) Promote the access of Internet-providers to international transcontinental optic-fiber cable systems.

The appearance of such agreement indicates that countries of Eastern and Southern regions of Africa try to elaborate the common strategy of the development of information technologies on their territory and to join their forces when creating a united information and communication space of East and South Africa. So the Kigalian protocol could become a document which would promote the intensification of integration processes in South and East Africa.

And what about Western and Central parts of the continent? We'd like to mark that all attempts of countries of West and Central Africa to elaborate a kind of joint "road map" concerning the development of the ICT sector have failed. In June 2005 in Dakar (Senegal) there took place an international symposium where they have decided to develop optic-fiber cable system in the region. But due to the lack of financial and technological resources this forum didn't elaborate any practical recommendations. To our opinion it was rather predictable because it was the Central part of the continent where there have been situated the poorest countries of the region. And it is evident that it would be very difficult to include such countries into the global information and communication space.

That's why in order to promote the development of the ICT sector on the continent as a whole; countries of Eastern and Southern Africa have decided to give an opportunity for African countries of Central and Western parts of the continent to join the Protocol. The appropriate resolution has been signed on October 15, 2007 in Johannesburg (South Africa) on the meeting of Ministers of countries which have signed the Protocol. On this meeting they have underlined that the Kigalian protocol doesn't concern the development of optic-fiber cable system only on the South and East Africa. Any country can join the Protocol. That's why it is a real possibility that the Kigalian protocol can become, in the future, a document which would initiate the process of real Pan-African integration and the cooperation between all African countries. To our opinion, it is rather possible. This document is aimed on the solution of the common problem of every state. Taking into account the scarcity of the realization of the project of the development of optic-fiber cable system in Africa from one side and the limited financial and technological base of African countries from another side, it is evident that the most realistic way of the creation of the well-developed information and communication infrastructure in Africa is to join forces by African countries. That's why the words of the first president of Ghana nowadays didn't lose their actuality. It is obvious that only the real unity of African countries can ensure an independent development of the ICT industry in Africa. Otherwise African countries will remain on the periphery of the world informational and communicational space and finally lose their identity.

\section{Conclusion}

To conclude we'd like to mark that if Sub-Saharan countries pretend to become an equal part of global information and communication space, they should avoid of choosing the model of the information society 
which would be based on the Western pattern of the development. The history of African states has shown a fiasco of concepts of the "catching up with the development" and the "structural reconstruction of the economy" of African countries. That's why we argue that African model of the information society should be based on local values and views. Only in that case information technologies will become a real instrument which can ensure a sustainable social and economic growth but not the new mechanism of strengthening of financial and technological dependence of Sub-Saharan countries from their more developed Western partners.

It is necessary to mark that nowadays African states often declare the desire to determine key priorities of the social and economic development of the continent. Well-developed nations have supported this initiative and agreed to support plans of actions and strategies of the development elaborated by African countries themselves. But in fact almost all regional and national plans of the development represent simple following recommendations elaborated on big international forums such as "G8" and summits "EU-Africa". This fact gives us a possibility to conclude that Africa still waits when global community would find an appropriate solution of the most significant challenges of the continent, such as the problem of the development of information and communication infrastructure. But even if such solution would be found, it would mean the global solution of the global problem but not the African solution of the African problem and it may cause the construction of the kind of the information society where only political and business elites would get the real benefit from the usage of information technologies whereas public at large won't have an access to information and telecommunication systems and means of communication and would remain on the periphery of the global information and communication space.

It is evident that in order to overcome the technological gap with well-developed nations and to ensure an independent development, African countries should come through enormous work closely associated with great difficulties. In general they need to think about the realization of following key points:

(1) Create an adequate informational and communicational infrastructure that should become a technological backbone of the Information Society. In our opinion the main problem is to overcome the digital gap between rural and urban areas of African countries and to give an opportunity for the vast majority of African citizenry to participate in global exchange of information;

(2) Elaborate a modern system of computer courses aimed on the increase of computer literacy of African population;

(3) Elaborate and to start implementing basic principles of the E-government;

(4) Start to create local digital content in local languages;

(5) Begin to produce local technologies (hardware and software) which would be maximally adapted to the necessity of African citizenry.

It is hard to underline the key priority. Only the realization of all these points can lead to the construction of the well-developed, self-reliant and independent digital society in the region. But it is evident that when realizing all those projects it is necessary to try to minimize the presence of foreign investors in the ICT sector which one should concern as a strategic one. First of all, our first point is that States of Sub-Saharan Africa should elaborate favorable conditions for attraction of local, African, investments into the ICT industry.

The second point is that the State should preserve its regulatory function. The policy of full liberalization is very dangerous process. The national government should elaborate legislative rules in order not only to regulate the activity of private companies but to put under control the process of the liberalization of the ICT sector itself. 
We don't recommend the establishment of state monopolies. There should be a multiple choice of mobile operators, Internet and infrastructural providers. But it is the government which declares certain rules for the future development of the ICT industry. We'd like recommend diversifying the competencies. The national optic-fiber backbone should remain in governmental property. And it is the state which is busy in construction, maintains and modernization of main telecommunication lines in the country. Maybe it would be effective to create special public companies which would become owners of these telecommunication lines. Of cause it is important to attract foreign investments when constructing the technological backbone of African telecommunication infrastructure. So Western corporations can participate in these national companies but the government should remain the main shareholder in such companies.

But there are national corporations which should become major infrastructural providers in the country. They should distribute telecommunication services to private mobile phone operators and Internet providers which would provide telecommunication services to final distributers. It is private business which should find solutions how to increase the quality of telecommunication services, to extend mobile coverage in the country and to provide the "technology of last mile" from main optic-fiber lines which remain in governmental property to every household. To our opinion, this should be the real feature of public-private partnership. But we'd like to repeat once more that the quota of foreign (non-African) investments in such projects should be strictly limited. The creation of favorable conditions for the development of local business, especially in the ICT sector should become the key priority of the State.

Only in that case it will appear a hope to create an independent African information and communication infrastructure with very weak participation of foreign investors. And African countries will be able, finally, to ensure the independent development of their information and communication space. Otherwise it may lead to the growth of the abovementioned dependence from foreign investors which impede the further sustainable social and economic growth of Sub-Saharan countries.

\section{References}

Adamu, A. U. (2007). Trans-global media flows and African popular culture. Kano, Nigeria.

Chasia, H. (2005). NEPAD e-Africa Commission's submission to the Joint Facilitation Meeting on WSIS. Geneva.

International Telecommunication Union. (2007). Retrieved from http://www.itu.int/wsis/c2/docs/ 2007-May-16/documents/ALC2C4C6_3_11-NEPADf.pdf

Kenya Vision 2030. (n.d.). Retrieved from http://www.vision2030.go.ke/index.php

Kermeliotis, T. (2013). Africa's tallest building set for $\$ 10$ billion tech city. Retrieved March 20, 2013, from http://edition.cnn.com/2013/03/20/tech/hope-city-ghana

Konza Techno City. (n.d.). Retrieved from http://www.konzacity.co.ke

NEPAD E-Africa Commission. (2014). Retrieved from http://www.eafricacommission.org

Nigeria Vision 2020. (n.d.). Retrieved from http://www.africaportal.org/sites/default/files/NigeriaVision2020_0.pdf

Nkrumah, K. (2007). Africa must unite. London: PANAF.

The Ghana ICT for accelerated development policy. (n.d.). Retrieved from http://www.nca.org.gh/downloads/Ghana_ICT4AD_Policy.pdf 